\title{
Event-Related Potential Responses to Beloved and Familiar Faces in Different Marriage Styles: Evidence from Mosuo Subjects
}

\author{
Haiyan Wu ${ }^{1,2}$, Li Luo $^{3}$, Junqiang Dai ${ }^{3}$, Suyong Yang ${ }^{4}$, Naiyi Wang ${ }^{5}$ and Yue-jia Luo ${ }^{6,7 *}$ \\ ${ }^{1}$ Key Laboratory of Behavioral Science, Institute of Psychology, Chinese Academy of Sciences, Beijing, China, ${ }^{2}$ State Key \\ Laboratory of Cognitive Neuroscience and Learning, Beijing Normal University, Beijing, China, ${ }^{3}$ School of Education, \\ Guangzhou University, Guangzhou, China, ${ }^{4}$ Key Laboratory of Exercise and Health Sciences of Ministry of Education, \\ Shanghai University of Sport, Shanghai, China, ${ }^{5}$ Institute of Educational Psychology and School Counselling, Beijing Normal \\ University, Beijing, China, ${ }^{6}$ Institute of Affective and Social Neuroscience, College of Psychology and Sociology, Shenzhen \\ University, Shenzhen, China, ${ }^{7}$ Institute of Neuroscience, Shenzhen, China
}

OPEN ACCESS

Edited by:

Zhiling Zou,

Southwest University, China

Reviewed by:

Yina $M a$,

Beijing Normal University, China

$\mathrm{LiHu}$,

Southwest University, China

*Correspondence:

Yue-jia Luo

luoyj@szu.edu.cn

Specialty section:

This article was submitted to

Cognitive Science,

a section of the journal

Frontiers in Psychology

Received: 16 July 2015 Accepted: 27 January 2016 Published: 17 February 2016

Citation:

Wu H, Luo L, Dai J, Yang S, Wang N and Luo Y-j (2016) Event-Related Potential Responses to Beloved and Familiar Faces in Different Marriage Styles: Evidence from

Mosuo Subjects.

Front. Psychol. 7:159.

doi: 10.3389/fpsyg.2016.00159
Research on familiar face recognition has largely focused on the neural correlates of recognizing a beloved partner or family member. However, no research has explored the effect of marriage style on the recognition of a beloved partner's face, especially in matriarchal societies. Here, we examined the time course of event-related potentials (ERP) in response to the face of a beloved partner, sibling, or unknown person in a sample of individuals from the matriarchal Mosuo tribe. Two groups were assessed: intermarriage and walking marriage groups (i.e., couples in a committed relationship who do not cohabitate during the daytime). In agreement with previous reports, ERP results revealed more positive VPP, N250, and P300 waveforms for beloved faces than sibling faces in both groups. Moreover, P300 was more positive for beloved partner versus sibling faces; however, this difference emerged at fronto-central sites for the walking marriage group and at posterior sites for the intermarriage group. Overall, we observed that marriage style affects the later stage processing of a beloved partner's face, and this may be associated with greater affective arousal and familiarity.

Keywords: love, affective processing, familiar faces, event-related potentials

\section{INTRODUCTION}

The experience of romantic love allows people to build passionate and intimate relationships. Based on previous theory, passion in romantic love is affected by intimacy and relationship duration (Baumeister, 1999; Graham, 2011). Generally, the early stages of romantic love involve intense and passionate emotions, and are later followed by companionate love and the formation of a stable commitment. Romantic love in a relationship is characterized by attachment, care-giving, and sexual attraction (Mikulincer and Goodman, 2006). Several neuroscience studies have proposed that the experience of love involves a neural network distinct from networks that process stimuli relevant to friendship or parental relationships (Bartels and Zeki, 2000, 2004; Aron et al., 2005; Ortigue et al., 2007). Other investigations have confirmed that the affective brain network (Bartels and Zeki, 2004) and reward pathway are correlated with the experience of romantic love (Fisher et al., 2002, 2005; Aron et al., 2005; Zeki and Romaya, 2010; Xu et al., 2011; Acevedo et al., 2012). 
Event-related potential (ERP) studies on the visual processing of a beloved partner's face have provided temporal information regarding the dynamic neural mechanisms underlying familiar face perception. Numerous face-processing studies have identified several early face-related ERP components, including N170, VPP (or P2), and N200 (Bruce and Young, 1986; Luo et al., 2010). P300 has also been identified as sensitive to facial familiarity and emotional arousal, and is an important identifier for self-relevant processing (Grasso et al., 2009; Grasso and Simons, 2011). Previous ERP studies assessing the recognition of a beloved partner's face have demonstrated that beloved faces elicit a more positive P300 or late positive potential (LPP) than control faces. For example, the LPP was larger when viewing beloved faces than viewing friends' faces, which was interpreted as a greater reflection of motivational attention toward the beloved face (Langeslag et al., 2007). A subsequent study utilizing an oddball paradigm to dissociate love-related attention from task-related attention also found that P300 was more positive for beloved faces than for friends' faces, irrespective of whether the beloved face was the target or the distracter stimulus (Langeslag et al., 2008). The authors concluded that perception of a beloved face is accompanied by increased motivational attention for evolutionary reasons (i.e., reproductive). Additionally, it has been proposed that perception of a beloved face is associated with enhanced affective processing (Vico et al., 2006, 2010; Vila et al., 2006). A popular view suggests that emotional stimuli evoke a more positive P300 than neutral stimuli do (Schupp et al., 2004; Pollatos et al., 2005; Eimer and Holmes, 2007). To test this hypothesis, Vico et al. (2010) measured peripheral and central electrophysiological indices, including EEG, heart rate, skin conductance, and zygomatic activity, when subjects viewed five face categories: neutral, unknown, famous, babies, and beloved. Results showed that P300 could differentiate a beloved face from other faces, and furthermore related a larger P300 to the allocation of greater attentional resources. In agreement, it is documented that beloved faces evoke greater arousal of positive emotions (Guerra et al., 2011b). Therefore, despite inconsistent interpretations of P300, there exists a clear association of P300 with the processing of beloved and familiar faces.

The majority of the aforementioned studies placed a focus on passionate or intense romantic love by using the faces of dating partners, where dating can be assumed to describe the early stage of a romantic relationship (de Boer et al., 2012; Langeslag et al., 2015). A recent fMRI study explored the neural correlates of long-term romantic love by evaluating participants that had been married for more than 21 years (Acevedo et al., 2012). Results indicated that activation in reward regions (e.g., the ventral tegmental area and dorsal striatum) is similar in early stage love and long-term love. However, long-term love also involves attachment and pair-bonding-related brain networks (Acevedo et al., 2012). Therefore, it can be hypothesized that brain responses toward beloved faces shift with increasing intimacy and the stage of the relationship. However, few studies have examined brain responses following the recognition of a beloved partner in the context of a long-term relationship, wherein the spouse may be perceived as a family member. In consideration of "love phases" (de Boer et al., 2012), the present study included participants whose relationships had lasted at least seven years (Sternberg, 1987; García, 1998). Therefore, the first aim of the present study was to investigate neural face recognition responses among companionate love partners in stable relationships.

To our knowledge, few studies have investigated whether marriage style modulates the recognition of beloved and familiar faces. China's Mosuo tribe, which follows a matriarchal culture, provides a unique opportunity for the investigation of marriage style and partner face recognition. In the Mosuo tribe, women are often the head of the household, and inheritance is conveyed through the female line. More interestingly, members of the Muoso tribe are allowed to select between two marriage styles. Several members of the Mosuo tribe maintain a "walking marriage" lifestyle in which there are no husbands or wives, and romantic partners do not live together during the daytime (Yuan and Mitchell, 2000; Walsh, 2001). For instance, a man will stay with his partner during the night and return home early the next morning. The "walking marriage" relationship is somewhat secretive and accordingly does not include economic or childbearing responsibilities. Instead, siblings live together and rear each other's children, forming a family unit. In contrast, other Mosuo tribe members choose "intermarriage", which more closely represents a typical modern marriage. In an intermarriage, the married couple cohabitates and forms a core family unit that includes a husband, a wife, and children. Compared to intermarriage, a romantic partner in a walking marriage may be met with higher novelty and arousal. Therefore, different marriage and cohabitation styles may be associated with different neural responses to partner and family member faces. Specifically, we predicted that familiarity responses to a sibling should be higher for people who practice walking marriage than for people who practice intermarriage.

The present study used sibling faces as contrast stimuli to control for familiarity, age, gender, and affective affiliation. To explore neural responses to a beloved partner in Mosuo tribe members, we compared ERP responses to three types of faces (partners, siblings, and unknown persons) during a face discrimination task. We hypothesized that faces of a beloved partner would engender more attention or affective processing than sibling faces. Additionally, we predicted that familiarity processing of a family member's face would be modulated by marriage style.

\section{MATERIALS AND METHODS}

\section{Participants}

Forty-five healthy adult Mosuo tribe members participated in the study as paid volunteers. Four participants were excluded due to excessive artifacts or missing data, leaving 41 participants in the following statistical analysis. The walking marriage group consisted of 10 males $(M=37.5$ years, $S D=2.72)$ and 10 females $(M=34.4$ years, $S D=5.89)$. The intermarriage group consisted of 12 males $(M=36.2$ years, $S D=3.1)$ and 9 females $(M=33.4$ years, $S D=6.44)$. All participants were in 
a stable relationship for more than 7 years, had children with their partners, and reported an exclusive relationship. Signed informed consent was obtained from all subjects prior to testing in accordance with the Beijing Normal University Review Board guidelines.

\section{Stimuli}

For each participant, the stimulus set included seven digital images (the face of one's heterosexual lover, the face of one's opposite-sex sibling, and five faces of unknown oppositesex Mosuo people). All photographs were taken before the experiment using the same digital camera and background. Faces showed a neutral expression and were processed by Adobe Photoshop CS4 to match brightness, contrast, and size within the stimulus set.

\section{Procedure}

Participants were seated $70 \mathrm{~cm}$ from the computer screen and stimuli were presented in the center of a 14-inch screen with a visual angle of $4.3^{\circ} \times 4.6^{\circ}$. A modified oddball and choice reaction paradigm was utilized. The beloved and sibling faces were targets, and the stranger faces were non-target stimuli. Participants were asked to press "F" or "J" in response to their beloved partner or sibling, respectively. The response button was counterbalanced across participants. That is, half of the participants pressed " $F$ " to indicate a beloved partner while the other half pressed "J" to indicate a beloved partner. To evaluate P300, we also manipulated the ratio of face category presentation to be 1:1:5 (beloved partner vs. sibling vs. stranger) for three face categories. Each face was presented 60 times; accordingly, the study consisted of 420 trials. In each trial, a white fixation cross was first presented on a black background for $300 \mathrm{~ms}$, followed by a randomly varied interval of 300$500 \mathrm{~ms}$. Subsequently, a face was presented for $3000 \mathrm{~ms}$ and the participants were asked to respond to the target stimulus as soon as possible. The face disappeared upon response within the $3000 \mathrm{~ms}$ interval. The trial ended with a randomly varied interval of 300-500 ms.

\section{Electroencephalogram Recording and Data Analysis}

Electroencephalograms (EEGs) were recorded using a 64-channel BrainAmp MR with online reference to the left mastoid. Vertical electrooculograms (VEOGs) were recorded from two electrodes positioned above and below the left eye, and horizontal electrooculograms (HEOG) were recorded from two laterally placed electrodes for both eyes. All electrode impedance was maintained below $10 \mathrm{k} \Omega$ and the EEG signals were recorded with a band pass of $0.01-100 \mathrm{~Hz}$ and sampled at $500 \mathrm{~Hz} / \mathrm{channel}$. All electrodes were re-referenced to the average of the bilateral mastoids and filtered offline with a low pass of $30 \mathrm{~Hz}$. EEGs were segmented from $200 \mathrm{~ms}$ prior to stimulus presentation until $1000 \mathrm{~ms}$ post-stimulus presentation. Trials containing blinks or eye movements $( \pm 80 \mu \mathrm{V})$ were excluded. The mean left trial number was 53.02 and 54.43 for the beloved partner and sibling conditions, respectively. The grand average ERPs suggested that the face of a beloved partner evoked a more positive potential than the face of a sibling from 200-600 ms (see Figure 1). We also observed VPP and N250 over fronto-central sites $(\mathrm{Cz}$, C3, C4, Fz, F3, F4, FCz, FC3, and FC4). Therefore, we first averaged an individual's mean ERP over fronto-central sites, and then interpreted the local maximum between 150 and $200 \mathrm{~ms}$ to be the latency of VPP. Subsequently the amplitude at that specific latency was taken at each individual electrode to calculate amplitude of VPP. We also interpreted the local minimum between 200 and $300 \mathrm{~ms}$ to be the latency of N250, and the amplitude at that specific latency was qualified as the amplitude of N250. Considering that the trial number of stranger faces was far greater than that of the other two conditions, and did not require a motor response, we excluded stranger faces from the ERP analysis and focused on the distinctions between beloved partner and sibling face recognition. VPP and N250 were evaluated using a mixed ANOVA with group (walking marriage vs. intermarriage) as the between-subject variable and face category (beloved partner vs. sibling) as the within-subject variable. Given that P300 is a widely distributed component, and that previous studies have dissociated anterior P300 from posterior P300 (Halgren et al., 1998; Friedman et al., 2001; Gaeta et al., 2003; Bobes et al., 2007; Polich, 2007; Cano et al., 2009), we selected Cz, C3, C4, FCz, FC3, FC4, Fz, F3, and F4 in order to analyze the anterior P300 (mean amplitude, 350$600 \mathrm{~ms}$ ), and Pz, P3, P4, POz, PO3, PO4, CPz, CP3, CP4 in order to analyze the posterior P300 (mean amplitude, 350-600 ms). The P300 amplitude was evaluated using a mixed ANOVA with group (walking marriage vs. intermarriage) as the betweensubject variable and face category (beloved partner vs. sibling) and location (anterior vs. posterior) as within-subject variables.

\section{RESULTS}

\section{Behavioral Results}

Incorrect trials and individual response times (RTs) exceeding 3 -times the standard deviation $(S D)$ were excluded (less than $2 \%)$. Furthermore, preliminary analyses revealed no significant effect of gender (all $F s<3$, ps $>0.09$ ) on any variable. Thus, all analyses were collapsed across gender. Accuracy and intraindividual mean RTs within categories were computed and entered into separate mixed two-way ANOVAs (face category by group). Since no significant effects were identified, we conducted planned paired $t$-tests (beloved partner vs. sibling) to examine within-group differences.

Response times were significantly different for beloved versus sibling face discrimination in the walking marriage group $\left(t_{19}=2.66, p<0.05\right)$. Walking marriage participants showed longer response times for the beloved face $(M=671 \mathrm{~ms}$, $S E=23.48)$ as compared to the sibling face $(M=653 \mathrm{~ms}$, $S E=21.24)$. No significant differences were observed in the intermarriage group.

\section{VPP}

The ANOVA for frontal-central VPP amplitude revealed a significant main effect of face category, $F(1,39)=14.73$, 

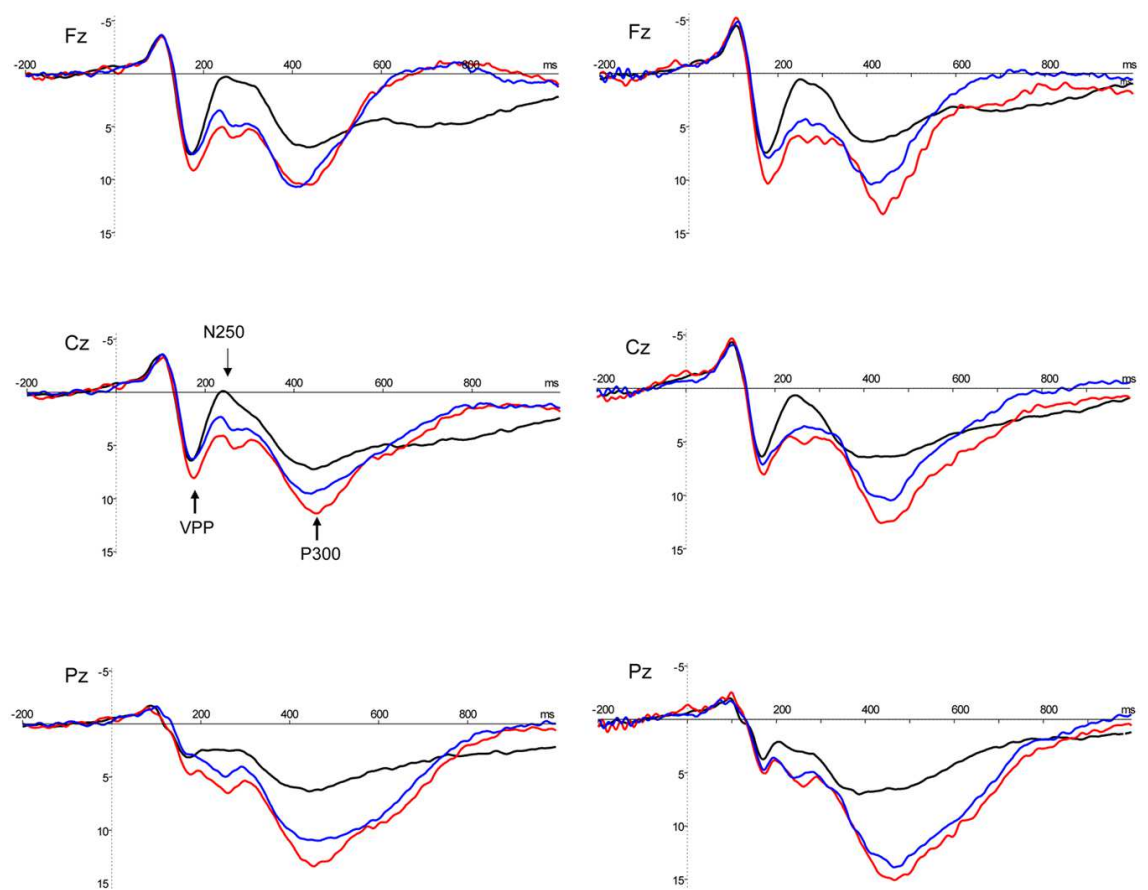

Intermarriage

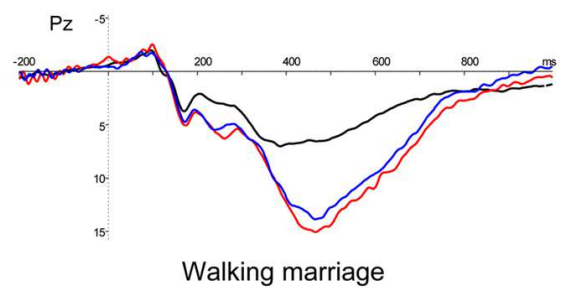

— Stranger - Sibling - Beloved partner

FIGURE 1 | Grand average ERPs at Fz, Cz, and Pz for two groups. Familiar faces (beloved and sibling) evoked more positive brain potentials than strangers from 200 to 600 ms for all sites. P300 (marked gray) was more positive for beloved face than sibling for both groups.

$p<0.001, \eta_{\mathrm{p}}^{2}=0.27$, indicating that beloved faces elicited larger VPPs $(M=9.67 \mu \mathrm{V}, S E=0.69)$ than sibling faces $(M=8.24 \mu \mathrm{V}$, $S E=0.69)$. No significant group effect was observed.

\section{N250}

Analyses of N250 also showed a significant main effect of face category, $F(1,39)=5.71, p<0.05, \eta_{\mathrm{p}}^{2}=0.13$. Sibling faces evoked a larger $\mathrm{N} 250(M=0.26 \mu \mathrm{V}, S E=0.74)$ than beloved partner faces $(M=2.19 \mu \mathrm{V}, S E=0.70)$.

Considering the observed effect of face category on VPP, we also measured the peak-peak amplitude of N250 to exclude any VPP influences. Results indicated no significant effect of face category and no group effect was observed, $F s<0.84$, ps $>0.37$.

\section{P300}

P300 amplitude was evaluated using a mixed ANOVA with group (walking marriage vs. intermarriage) as a between-subject variable and face category (beloved vs. sibling) and location (anterior vs. posterior) as within-subject variables. We found a significant main effect of face category, $F(1,39)=18.98, p<0.01$, $\eta_{\mathrm{p}}^{2}=0.33$, indicating an overall larger P300 for beloved faces. There was also a significant location effect, $F(1,39)=10.51$, $p<0.01, \eta_{\mathrm{p}}^{2}=0.21$, which identified a larger P300 at anterior sites. While no significant group effect was observed, we did identify a significant three-way interaction, $F(1,39)=5.77$, $p<0.05, \eta_{\mathrm{p}}^{2}=0.13$. Post hoc analyses indicated that, for the intermarriage group, the posterior P300 amplitude was larger for beloved faces $(M=9.86 \mu \mathrm{V}, S E=1.17)$ than sibling faces $(M=8.78 \mu \mathrm{V}, S E=1.14)$. For the walking marriage group, the anterior P300 amplitude was larger for beloved faces $(M=9.93 \mu \mathrm{V}, S E=1.22)$ than sibling faces $(M=8.75 \mu \mathrm{V}$, $S E=1.23)$.

Electrophysiological results for the P300 component in both groups and scalp voltage topography for the beloved $v s$. sibling difference waves (P300) are summarized in Figure 2. The topography map confirmed that the beloved vs. sibling P300 difference occurred mainly at posterior sites in the intermarriage group, while P300 differences only occurred at anterior sites in the walking marriage group. Interestingly, we primarily identified a differential pattern between beloved and sibling faces over the left frontal brain area. To validate this observation, we conducted an electrode side (left: F3, FC3, and C3 vs. right: F4, FC4, and C4) $\times$ face type ANOVA on the anterior P300. Results showed a significant electrode side effect on the anterior P300, $F(1,39)=5.77, p<0.05, \eta_{p}^{2}=0.13$, such that a more positive $\mathrm{P} 300$ was observed in the right fronto-central area versus the left.

\section{DISCUSSION}

The present study examined ERP responses to the face of a beloved partner or sibling in Mosuo tribe members practicing 
A $\square$ Beloved Parterner $\square$ Sibling

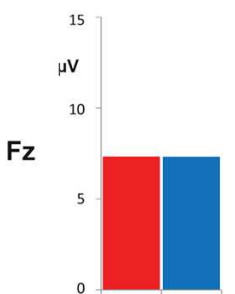

$\left.{ }_{10}^{15}\right]$

$\mathrm{FCz}$

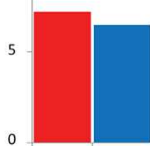

15

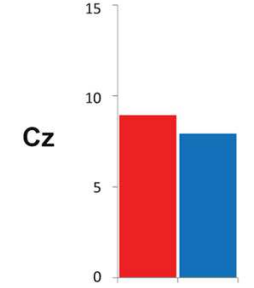

15
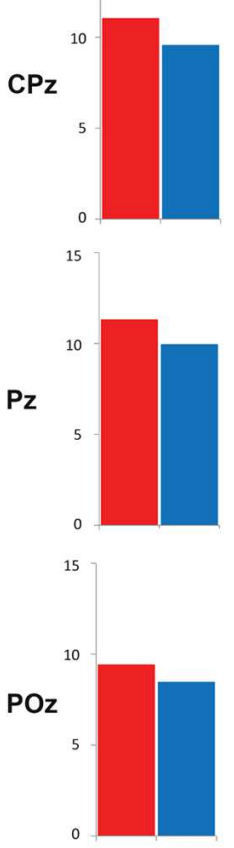

Intermarriage

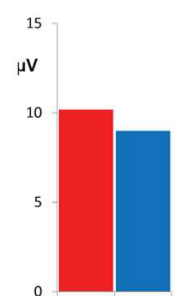

15

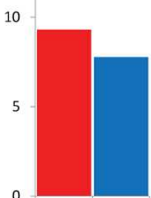

15
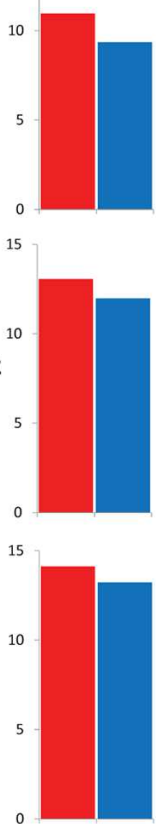

15

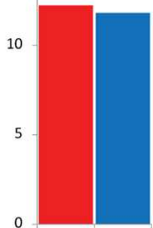

Walking marriage
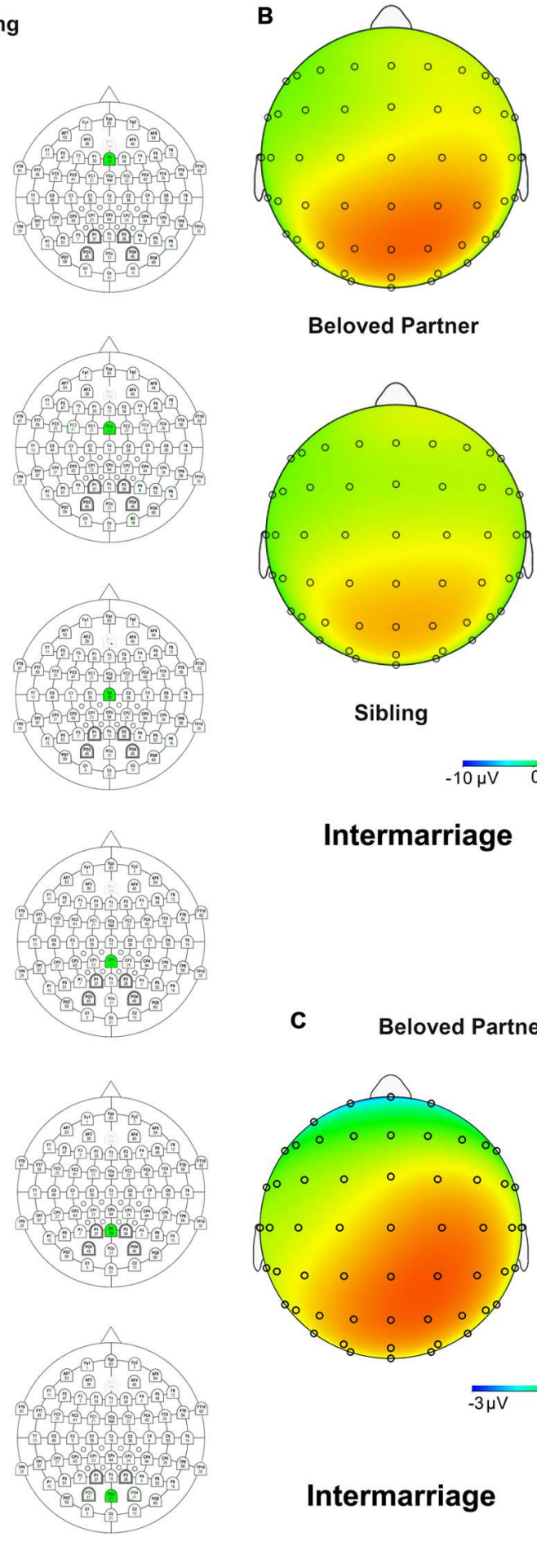

Beloved Partner

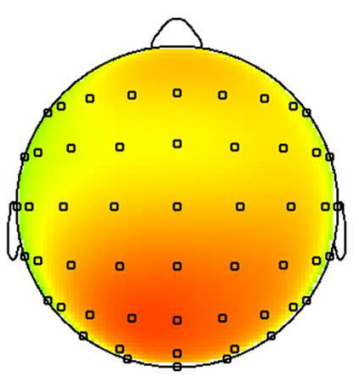

Beloved Partner
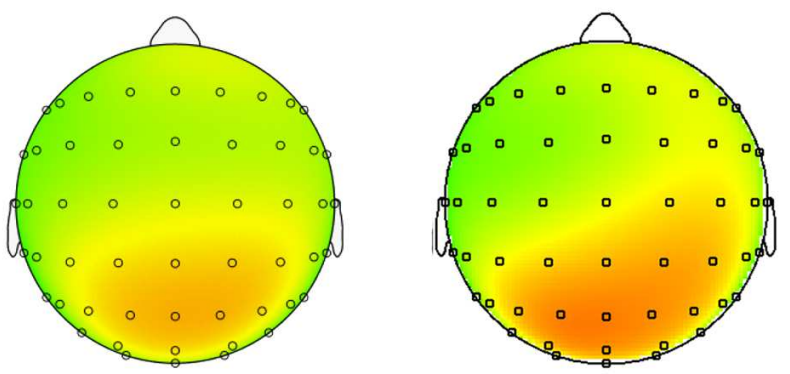

Sibling

Sibling

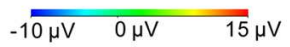

Intermarriage

Walking marriage

FIGURE 2 | (A) The P300 amplitude in the midline electrodes. The bars indicates the mean P300 amplitude at Fz, FCz, Cz, CPz, Pz, and POz (corresponding electrode was marked as green in column III); (B) The topography of P300 for grand averaged face conditions (beloved partner vs. sibling) for two groups; (C) The topography of difference wave of P300 (beloved partner vs. sibling) for two groups. The topography map indicated that the beloved partner vs. sibling P300 difference mainly occurs at posterior sites (also at some frontal sites) for intermarriage group while the difference only occurs at anterior sites for walking marriage group. The figure indicates that the beloved partner vs. sibling difference changes from the anterior to posterior sites. Such difference is larger at posterior sites for intermarriage group, while the difference is larger at anterior sites for walking marriage group. 
walking marriage or intermarriage. Results indicated that individuals in the walking marriage group exhibited slower response times to beloved faces than sibling faces. One possible interpretation is that walking marriages represent a less secure relationship than a familial sibling relationship. The potential secrecy associated with a walking marriage may cause individuals to associate a beloved face with greater novelty, and thus lead to slower reaction times during an explicit face judgment task. Notably, we observed no differences in recognition accuracy between groups or between faces. This may suggest a "ceiling effect" in the face task, as mean accuracy (96.9\%) was very high across groups and conditions.

With regard to ERP results, beloved faces were associated with more positive ERP potentials than sibling faces from $200 \mathrm{~ms}$ to the late processing stage (VPP, N250, and P300). VPP at centrofrontal sites, occurring between 150 and $200 \mathrm{~ms}$ post-stimulus presentation, is often regarded as similar to N170 (Rossion et al., 1999, 2003; Itier and Taylor, 2002; Jemel et al., 2003; Joyce and Rossion, 2005). Although some studies have reported that VPP is not modulated by emotional stimuli (Rossignol et al., 2005) or familiarity (Rossignol et al., 2005; Sui et al., 2006; Marzi and Viggiano, 2007), results from expression processing studies suggest that VPP is subject to modulation by affectively salient stimuli (Ashley et al., 2004; Williams et al., 2006; Foti et al., 2010). Therefore, enhanced VPP amplitudes observed in response to a beloved partner's face might reflect affective salience in early perception.

VPP enhancement in response to a beloved face likely influenced the effect observed for N250, as the peak-peak N250 amplitude revealed no significant effect. N250 (or N300 in some studies) has been reported to be sensitive to facial familiarity (Schweinberger et al., 1995; Tanaka et al., 2006; Krigolson et al., 2009) and affective features (Eimer and Holmes, 2002, 2007). While N250 results are in accordance with previous studies demonstrating that beloved faces (fathers and romantic partners) are associated with smaller N200s (Guerra et al., 2011a), we conjecture that the N250 effect in our study was due to VPP enhancements after viewing the face of a beloved partner.

Clearly, the P300 component discriminated the perception of familiar faces from unknown faces in our study, as familiar faces elicited a more positive P300. This effect is consistent with several previous studies (Langeslag et al., 2007, 2008; Guillaume et al., 2009). Furthermore, enhancements in the amplitude of P300 were greater in response to the face of a beloved partner versus a sibling. We speculate that a beloved partner provides more intimate/self-relevant significance, regardless of marriage type. We did however identify a dissociation of anterior P300 from posterior P300 based on marriage type. An enhanced posterior P300 amplitude was observed for beloved partner versus sibling faces in the intermarriage group, while the anterior P300 amplitude was more positive for beloved partner versus sibling faces in the walking marriage group. The anterior and posterior P300 components may reflect differences in psychological significance. The posterior P300, which is more akin to classic P300 (e.g., peaking at parietal sites), may reflect face familiarity or a memory process that discriminates the familiar from the unfamiliar (Miyakoshi et al., 2007; Guillaume et al., 2009). On this premise, it is unsurprising that the intermarriage group showed widely distributed differences in P300 response to beloved partners versus siblings, especially in the posterior P300 (see Figure 2). Compared to the walking marriage group, a beloved partner in the intermarriage group may be of higher familiarity than siblings as a result of cohabitation and child rearing. There was no significant beloved partner versus sibling difference in the posterior P300 for the walking marriage group. This is likely because familiarity was more closely matched between one's beloved partner and sibling in the walking marriage group, relative to intermarriage group. Consequently, the posterior P300 result could be interpreted as a memory-related component in which a person of higher familiarity is correlated with larger P300 amplitudes.

The anterior P300 over fronto-central sites is more akin to a $\mathrm{P} 3 \mathrm{a}$ component, which reflects orientation responses toward novel stimuli (Friedman et al., 2001; Polich, 2007; Weisman et al., 2012). Our most remarkable finding was that the anterior P300 was enhanced in response to beloved partner versus sibling faces in the walking marriage group. This anterior P300 effect fits well with our hypothesis of a partner-viewing novelty effect in the walking marriage group, wherein limited contact (i.e., only at night) produces enhanced arousal toward the beloved partner's face. The beloved partner versus sibling difference was not significant for the anterior P300 in the intermarriage group. This may be attributed to the cohabitation environment, as intermarried couples have extensive contact with their partner, which is likely to decrease partner-face novelty.

On the other hand, neuroimaging studies have demonstrated that romantic love involves affective state-related brain regions, including the anterior cingulate cortex, the orbitofrontal cortex (OFC), and the striatum/reward system (Aron et al., 2005; Fisher et al., 2005; Xu et al., 2011; Acevedo et al., 2012). These regions, mostly within fronto-central areas, may contribute to the perception of beloved faces. Given the observation of differences in the response of anterior P300 to beloved partner versus sibling faces, we agree with Guerra et al. (2011b) that the frontal P300 may relate more specifically to the perception of a beloved partner's face.

Interestingly, we also observed overall left-right anterior P300 differences in the walking marriage group for responses to beloved versus sibling faces (see Figure 2). Lateralization over left fronto-central cites may be indicative of emotion-motivation system involvement, as asymmetric frontal cortical activity is correlated with affective experience (Harmon-Jones et al., 2011). Specifically, approach motivation is more significantly associated with left frontal cortical activity (Hewig et al., 2004). Another previous study demonstrated that appetitive pictures evoke a larger LPP than neutral pictures over left frontal sites (Gable and Harmon-Jones, 2010). Therefore, our observation that the face of a beloved partner produces a larger P300 over left fronto-central sites is supportive of our interpretation that the anterior P300 reflects an orienting response toward motivational stimuli. 
One limitation of present study is the absence of familiarity and affect ratings from both groups. We chose not to collect this data due of the conservative nature of our population and the "taboo" nature of sex-related questions. Therefore, we cannot definitively attribute P300 effects to familiarity or affective feelings. Further studies using subjective ratings and behavioral data are needed to validate our findings. Further, the lack of a normal, non-Mosuo marriage group to control for minority or tribe-related effects limits our ability to make inferences regarding P300 in other populations.

In summary, the present study provides a unique examination of companionate and sibling love, and reveals that ERPs can differentiate beloved partners from siblings in the early and late stages of processing. The VPP and N250 ERP components are thought to discriminate the perception of familiar individuals from unfamiliar individuals. In our study, more positive VPP and N250 values were not only observed for familiar versus unknown faces, but also for beloved partner versus sibling faces; thus, these components indicate early face configuration and identification processing of a beloved partner. In line with previous studies, P300 was also sensitive to beloved faces, and furthermore we differentiated anterior and posterior P300s in individuals

\section{REFERENCES}

Acevedo, B. P., Aron, A., Fisher, H. E., and Brown, L. L. (2012). Neural correlates of long-term intense romantic love. Soc. Cogn. Affect. Neurosci. 7, 145-159. doi: $10.1093 /$ scan/nsq092

Aron, A., Fisher, H., Mashek, D. J., Strong, G., Li, H., and Brown, L. L. (2005). Reward, motivation, and emotion systems associated with earlystage intense romantic love. J. Neurophysiol. 94, 327-337. doi: 10.1152/jn.008 38.2004

Ashley, V., Vuilleumier, P., and Swick, D. (2004). Time course and specificity of event-related potentials to emotional expressions. Neuroreport 15, 211-216. doi: 10.1097/00001756-200401190-00041

Bartels, A., and Zeki, S. (2000). The neural basis of romantic love. Neuroreport 11, 3829-3834. doi: 10.1097/00001756-200011270-00046

Bartels, A., and Zeki, S. (2004). The neural correlates of maternal and romantic love. Neuroimage 21, 1155-1166. doi: 10.1016/j.neuroimage.2003.11.003

Baumeister, R. F. (1999). Passion, intimacy, and time: passionate love as a function of change in intimacy. Pers. Soc. Psychol. Rev. 3, 49-67. doi: 10.1207/s15327957pspr0301_3

Bobes, M. A., Quinonez, I., Perez, J., Leon, I., and Valdes-Sosa, M. (2007). Brain potentials reflect access to visual and emotional memories for faces. Biol. Psychol. 75, 146-153.

Bruce, V., and Young, A. (1986). Understanding face recognition. Br. J. Psychol. 77(Pt 3), 305-327. doi: 10.1111/j.2044-8295.1986.tb02199.x

Cano, M. E., Class, Q. A., and Polich, J. (2009). Affective valence, stimulus attributes, and P300: color vs. black/white and normal vs. scrambled images. Int. J. Psychophysiol. 71, 17-24. doi: 10.1016/j.ijpsycho.2008. 07.016

de Boer, A., Van Buel, E. M., and Ter Horst, G. J. (2012). Love is more than just a kiss: a neurobiological perspective on love and affection. Neuroscience 201, 114-124. doi: 10.1016/j.neuroscience.2011.11.017

Eimer, M., and Holmes, A. (2002). An ERP study on the time course of emotional face processing. Neuroreport 13, 427-431. doi: 10.1097/00001756-20020325000013

Eimer, M., and Holmes, A. (2007). Event-related brain potential correlates of emotional face processing. Neuropsychologia 45, 15-31. doi: 10.1016/j.neuropsychologia.2006.04.022

Fisher, H., Aron, A., and Brown, L. L. (2005). Romantic love: an fMRI study of a neural mechanism for mate choice. J. Comp. Neurol. 493, 58-62. doi: $10.1002 /$ cne. 20772 with different marriage styles. The present study therefore demonstrates that early processing of a beloved partner's face is conserved across various relationship types, but affective or familiarity processing is subject to divergence in the late phase.

\section{AUTHOR CONTRIBUTIONS}

YJL and HW conceived the experiment, HW, LL, JD, and SY conducted the experiment, LL and HW analyzed the results. HW, NW, SY, and YJL wrote the paper. All authors reviewed the manuscript.

\section{ACKNOWLEDGMENTS}

This research was supported by grants from NSFC (31530031, 81471376), and the National Basic Research Program of China (2014CB744600) to YJL; the Startup Foundation for Young Talents of the Institute of Psychology (Y3CX172005), and the National Natural Science Foundation of China (NSFC) (31400963) to HW.

Fisher, H. E., Aron, A., Mashek, D., Li, H., and Brown, L. L. (2002). Defining the brain systems of lust, romantic attraction, and attachment. Arch. Sex. Behav. 31, 413-419. doi: 10.1023/A:1019888024255

Foti, D., Olvet, D. M., Klein, D. N., and Hajcak, G. (2010). Reduced electrocortical response to threatening faces in major depressive disorder. Depress. Anxiety 27, 813-820. doi: 10.1002/da.20712

Friedman, D., Cycowicz, Y. M., and Gaeta, H. (2001). The novelty P3: an eventrelated brain potential (ERP) sign of the brain's evaluation of novelty. Neurosci. Biobehav. Rev. 25, 355-373. doi: 10.1016/S0149-7634(01)00019-7

Gable, P. A., and Harmon-Jones, E. (2010). Late positive potential to appetitive stimuli and local attentional bias. Emotion 10, 441-446. doi: 10.1037/a0018425

Gaeta, H., Friedman, D., and Hunt, G. (2003). Stimulus characteristics and task category dissociate the anterior and posterior aspects of the novelty $\mathrm{P}_{3}$. Psychophysiology 40, 198-208. doi: 10.1111/1469-8986.00022

García, C. Y. (1998). Temporal course of the basic components of love throughout relationships. Psychol. Spain 2, 76-86.

Graham, J. M. (2011). Measuring love in romantic relationships: a meta-analysis. J. Soc. Pers. Relationsh. 28, 748-771. doi: 10.1177/0265407510389126

Grasso, D. J., Moser, J. S., Dozier, M., and Simons, R. (2009). ERP correlates of attention allocation in mothers processing faces of their children. Biol. Psychol. 81, 95-102. doi: 10.1016/j.biopsycho.2009.03.001

Grasso, D. J., and Simons, R. F. (2011). Perceived parental support predicts enhanced late positive event-related brain potentials to parent faces. Biol. Psychol. 86, 26-30. doi: 10.1016/j.biopsycho.2010.10.002

Guerra, P., Campagnoli, R. R., Vico, C., Volchan, E., Anllo-Vento, L., and Vila, J. (2011a). Filial versus romantic love: contributions from peripheral and central electrophysiology. Biol. Psychol. 88, 196-203. doi: 10.1016/j.biopsycho.2011.08.002

Guerra, P., Sanchez-Adam, A., Gonzalez, I., Anllo-Vento, L., and Vila, J. C. (2011b). Affective processing of loved familiar faces: an erp source analysis to identify frontal $\mathrm{P}_{3}$ generators. Psychophysiology 48, S26-S26.

Guillaume, C., Guillery-Girard, B., Chaby, L., Lebreton, K., Hugueville, L., Eustache, F., et al. (2009). The time course of repetition effects for familiar faces and objects: an ERP study. Brain Res. 1248, 149-161. doi: 10.1016/j.brainres.2008.10.069

Halgren, E., Marinkovic, K., and Chauvel, P. (1998). Generators of the late cognitive potentials in auditory and visual oddball tasks. Electroencephalogr. Clin. Neurophysiol. 106, 156-164. doi: 10.1016/S0013-4694(97)00119-3

Harmon-Jones, E., Gable, P. A., and Price, T. F. (2011). Leaning embodies desire: evidence that leaning forward increases relative left frontal 
cortical activation to appetitive stimuli. Biol. Psychol. 87, 311-313. doi: 10.1016/j.biopsycho.2011.03.009

Hewig, J., Hagemann, D., Seifert, J., Naumann, E., and Bartussek, D. (2004). On the selective relation of frontal cortical asymmetry and anger-out versus angercontrol. J. Pers. Soc. Psychol. 87, 926-939. doi: 10.1037/0022-3514.87.6.926

Itier, R. J., and Taylor, M. J. (2002). Inversion and contrast polarity reversal affect both encoding and recognition processes of unfamiliar faces: a repetition study using ERPs. Neuroimage 15, 353-372. doi: 10.1006/nimg.2001.0982

Jemel, B., Pisani, M., Calabria, M., Crommelinck, M., and Bruyer, R. (2003). Is the N170 for faces cognitively penetrable? Evidence from repetition priming of Mooney faces of familiar and unfamiliar persons. Cogn. Brain Res. 17, 431-446. doi: 10.1016/S0926-6410(03)00145-9

Joyce, C., and Rossion, B. (2005). The face-sensitive N170 and VPP components manifest the same brain processes: the effect of reference electrode site. Clin. Neurophysiol. 116, 2613-2631. doi: 10.1016/j.clinph.2005.07.005

Krigolson, O. E., Pierce, L. J., Holroyd, C. B., and Tanaka, J. W. (2009). Learning to become an expert: reinforcement learning and the acquisition of perceptual expertise. J. Cogn. Neurosci. 21, 1833-1840. doi: 10.1162/jocn.2009.21128

Langeslag, S. J., Franken, I. H., and Van Strien, J. W. (2008). Dissociating loverelated attention from task-related attention: an event-related potential oddball study. Neurosci. Lett. 431, 236-240. doi: 10.1016/j.neulet.2007.11.044

Langeslag, S. J., Jansma, B. M., Franken, I. H., and Van Strien, J. W. (2007). Event-related potential responses to love-related facial stimuli. Biol. Psychol. 76, 109-115. doi: 10.1016/j.biopsycho.2007.06.007

Langeslag, S. J. E., Olivier, J. R., Kohlen, M. E., Nijs, I. M., and Van Strien, J. W. (2015). Increased attention and memory for beloved-related information during infatuation: behavioral and electrophysiological data. Social Cogn. Affect. Neurosci. 10, 136-144. doi: 10.1093/scan/nsu034

Luo, W., Feng, W., He, W., Wang, N. Y., and Luo, Y. J. (2010). Three stages of facial expression processing: ERP study with rapid serial visual presentation. Neuroimage 49, 1857-1867. doi: 10.1016/j.neuroimage.2009.09.018

Marzi, T., and Viggiano, M. P. (2007). Interplay between familiarity and orientation in face processing: an ERP study. Int. J. Psychophysiol. 65, 182-192. doi: 10.1016/j.ijpsycho.2007.04.003

Mikulincer, M., and Goodman, G. S. (2006). Dynamics of Romantic Love : Attachment, Earegiving, and Sex. New York, NY: Guilford Press.

Miyakoshi, M., Nomura, M., and Ohira, H. (2007). An ERP study on self-relevant object recognition. Brain Cogn. 63, 182-189. doi: 10.1016/j.bandc.2006.12.001

Ortigue, S., Bianchi-Demicheli, F., Hamilton, A. F. D. C., and Grafton, S. T. (2007). The neural basis of love as a subliminal prime: an event-related functional magnetic resonance imaging study. J. Cogn. Neurosci. 19, 1218-1230. doi: 10.1162/jocn.2007.19.7.1218

Polich, J. (2007). Updating P300: an integrative theory of P3a and P3b. Clin. Neurophysiol. 118, 2128-2148. doi: 10.1016/j.clinph.2007.04.019

Pollatos, O., Kirsch, W., and Schandry, R. (2005). On the relationship between interoceptive awareness, emotional experience, and brain processes. Brain Res. Cogn. Brain Res. 25, 948-962. doi: 10.1016/j.cogbrainres.2005.09.019

Rossignol, M., Philippot, P., Douilliez, C., Crommelinck, M., and Campanella, S. (2005). The perception of fearful and happy facial expression is modulated by anxiety: an event-related potential study. Neurosci. Lett. 377, 115-120. doi: 10.1016/j.neulet.2004.11.091

Rossion, B., Campanella, S., Gomez, C. M., Delinte, A., Debatisse, D., Liard, L., et al. (1999). Task modulation of brain activity related to familiar and unfamiliar face processing: an ERP study. Clin. Neurophysiol. 110, 449-462. doi: 10.1016/S1388-2457(98)00037-6

Rossion, B., Joyce, C. A., Cottrell, G. W., and Tarr, M. J. (2003). Early lateralization and orientation tuning for face, word, and object processing in the visual cortex. Neuroimage 20, 1609-1624. doi: 10.1016/j.neuroimage.2003.07.010
Schupp, H. T., Ohman, A., Junghofer, M., Weike, A. I., Stockburger, J., and Hamm, A. O. (2004). The facilitated processing of threatening faces: an ERP analysis. Emotion 4, 189-200. doi: 10.1037/1528-3542.4.2.189

Schweinberger, S. R., Pfutze, E. M., and Sommer, W. (1995). Repetition priming and associative priming of face recognition - evidence from event-related potentials. J. Exp. Psychol. Learn. Mem. Cogn. 21, 722-736. doi: 10.1037/02787393.21.3.722

Sternberg, R. J. (1987). Liking versus loving - a comparative-evaluation of theories. Psychol. Bull. 102, 331-345. doi: 10.1037/0033-2909.102.3.331

Sui, J., Zhu, Y., and Han, S. H. (2006). Self-face recognition in attended and unattended conditions: an event-related brain potential study. Neuroreport 17 , 423-427. doi: 10.1097/01.wnr.0000203357.65190.61

Tanaka, J. W., Curran, T., Porterfield, A. L., and Collins, D. (2006). Activation of preexisting and acquired face representations: the N250 event-related potential as an index of face familiarity. J. Cogn. Neurosci. 18, 1488-1497. doi: 10.1162/jocn.2006.18.9.1488

Vico, C., Guerra, P., Anllo-Vento, L., Viedma-Del Jesus, M. I., and Vila, J. (2006). Viewing with the heart: affective processing of loved faces. J. Psychophysiol. 20, 248-249. doi: 10.1016/j.neuropsychologia.2010.05.031

Vico, C., Guerra, P., Robles, H., Vila, J., and Anllo-Vento, L. (2010). Affective processing of loved faces: contributions from peripheral and central electrophysiology. Neuropsychologia 48, 2894-2902. doi: 10.1016/j.neuropsychologia.2010.05.031

Vila, J., Vico, C., Munoz, M. A., Guerra, P., Mata, J. L., Rodriguez, S., et al. (2006). Psychophysiology of positive emotions: affective processing of loved faces. J. Psychophysiol. 20, 226-226.

Walsh, E. R. (2001). Living with the myth of matriarchy: the Mosuo and tourism. Tourism Anthropol. China 1, 93-124.

Weisman, O., Feldman, R., and Goldstein, A. (2012). Parental and romantic attachment shape brain processing of infant cues. Biol. Psychol. 89, 533-538. doi: 10.1016/j.biopsycho.2011.11.008

Williams, L. M., Palmer, D., Liddell, B. J., Song, L., and Gordon, E. (2006). The 'when' and 'where' of perceiving signals of threat versus non-threat. Neuroimage 31, 458-467. doi: 10.1016/j.neuroimage.2005.12.009

Xu, X., Aron, A., Brown, L., Cao, G., Feng, T., and Weng, X. (2011). Reward and motivation systems: a brain mapping study of early-stage intense romantic love in Chinese participants. Hum. Brain Mapp. 32, 249-257. doi: 10.1002/hbm. 21017

Yuan, L., and Mitchell, S. (2000). Land of the walking marriage. Nat. History 109, 58-64.

Zeki, S., and Romaya, J. P. (2010). The brain reaction to viewing faces of opposite- and same-sex romantic partners. PLoS ONE 5:e15802. doi: 10.1371/journal.pone.0015802

Conflict of Interest Statement: The authors declare that the research was conducted in the absence of any commercial or financial relationships that could be construed as a potential conflict of interest.

The reviewer, LH, and handling Editor declared their shared affiliation, and the handling Editor states that the process nevertheless met the standards of a fair and objective review.

Copyright (c) 2016 Wu, Luo, Dai, Yang, Wang and Luo. This is an open-access article distributed under the terms of the Creative Commons Attribution License (CC BY). The use, distribution or reproduction in other forums is permitted, provided the original author(s) or licensor are credited and that the original publication in this journal is cited, in accordance with accepted academic practice. No use, distribution or reproduction is permitted which does not comply with these terms. 